\section{Uma abordagem semiótica sobre o gênero de divulgação científica*}

\author{
A semiotic approach on the \\ scientific dissemination
}

Carolina Mazzaron de CASTRO (UNESP) carollcasttro@gmail.com Jean Cristtus PORTELA (UNESP) jean.portela@unesp.br

Recebido em: 02 de maio de 2018. Aceito em: 08 de dez. de 2018.

*Este trabalho conta com auxílio financeiro do CNPq e da FAPESP (processo n. $16 / 22466-0)$.

\section{0}

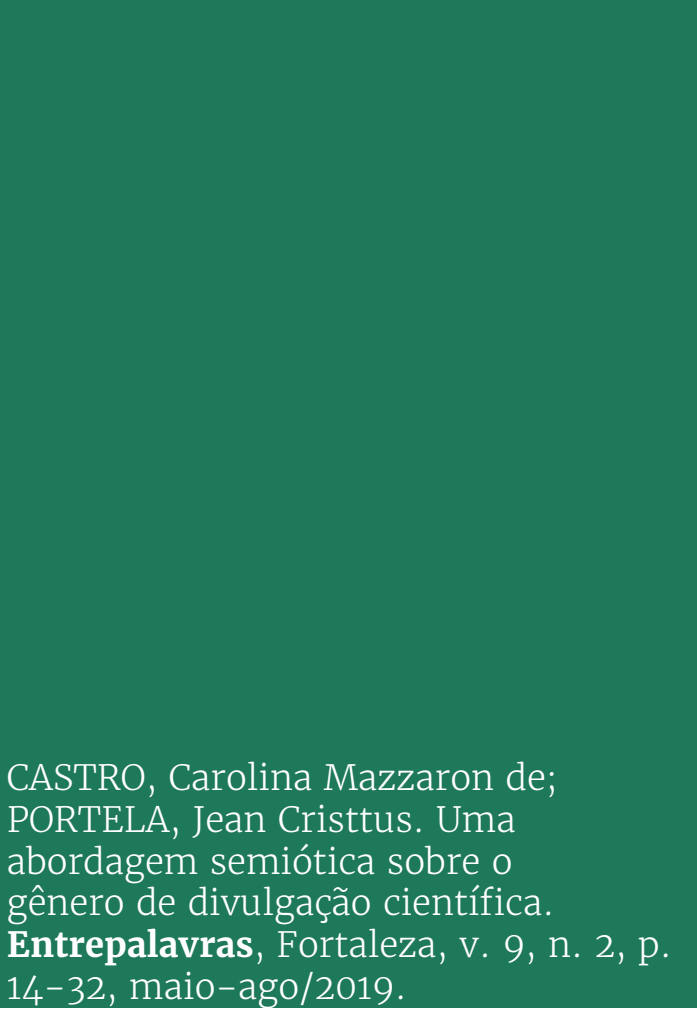

Resumo: Neste trabalho, propomos discutir a noção de gênero do ponto de vista semiótico, a partir do estudo da revista Actes Semiótiques (AS), cuja história está ligada ao surgimento da semiótica discursiva na França. Nosso objetivo é verificar de que forma esse periódico configura o gênero e a prática de divulgação científicos à luz dos critérios de análise textuais e discursivos propostos por J. Fontanille para o estudo do gênero. Considerando que a divulgação científica, como propõe S. Grillo, se faz por meio de gêneros sincréticos e, portanto, é formada pela relação entre o verbal e o não verbal, no plano do conteúdo e no plano da expressão, encontramos na AS todos os elementos que caracterizam a divulgação científica (textualidade verbal, diagramação, ilustração, etc.). O caso da AS é exemplar de como a internet enquanto suporte de periódicos científicos permite a construção de um enunciatário que não apenas lê, mas pratica a atividade científica: pesquisa, cruza dados e indexa autores e temas.

Palavras-chave: Actes Sémiotiques. Divulgação Científica. Práticas semióticas. 
Abstract: In this work, we propose to discuss the notion of genre from a semiotic point of view, based on the study of the Actes Sémiotiques (AS) journal, whose history is linked to the emergence of discursive semiotics in France. Our objective is to examine how this journal shapes the genre and the practice of scientific dissemination in the light of discursive and textual analysis criteria proposed by J. Fontanille for the study of the genre. Considering that scientific dissemination, as proposed by S. Grillo, is done through syncretic genres and, therefore, is formed by the link between verbal and nonverbal in the content plane and expression plane, we find in AS all the elements that characterize scientific dissemination (verbal textuality, diagramming, illustration, etc.). The AS's case is exemplary of how the Internet as a support of scientific journals allows the construction of an enunciatee that not only reads, but practices the scientific activity: researches, crosses data and indexes authors and themes.

Keywords: Actes Sémiotiques. Scientific divulgation. Practice semiotics.

\section{Introdução}

Neste artigo, temos como objetivo contribuir para as reflexões dos gêneros de discurso envolvidos na divulgação científica, na perspectiva de análise da semiótica discursiva. Partimos do pressuposto de que a divulgação científica é uma prática discursiva que, na sociedade contemporânea, vem se expandindo. Desse modo, julgamos pertinente pensar sobre questões da transmissão dos saberes científicos, sua constituição, manifestações e desdobramentos, na medida em que "insere[m] a ciência no conjunto das manifestações culturais de uma sociedade, o que implica a sua incorporação em práticas situadas sóciohistoricamente [...]"' (GRILLO, 2008, p. 69).

A divulgação científica é uma prática semiótica atrelada tanto à prática da comunicação científica (SANTOS; PORTELA, 2018), quanto à prática de produção do saber institucionalizado, cuja materialidade é o enunciado de gêneros variados, como: artigos, resenhas, traduções, editoriais, entrevistas, entre outros, e na maneira como o enunciado se estrutura. A própria concepção de divulgação é classificada da seguinte forma:

Divulgar [Do lat. divulgare.] 1.Tornar público ou notório; publicar; propagar, difundir, vulgarizar. [ . . ] 2. Tornar-se público ou conhecido; propagar-se, difundir- se [Var. ant.: devulgar. Conjug.: v. largar.] (FERREIRA, 2004).

Divulgar vb. 'vulgarizar, tornar conhecido, propalar, publicar' | devulgar XV | Do lat. divulgare || divulgaÇÃO 1873. Do lat. divulgatîo-onis ${ }^{-} \|$divulgaDOR 1813. Do lat. Divulgator- ${ }^{-}$oris (CUNHA, 1982, p. 273, grifo nosso). 
V. 9 (2)

14-32 maio-ago 2019

Considerando que a divulgação científica, tal como propôs Jacobi (1987), se insere na regulação do campo científico, a hipótese é de que os gêneros de discurso envolvidos na divulgação científica assumem a posição de mediadores competentes entre o saber científico institucionalizado e a atividade de produção científica, tendo como particularidade a transmissão da ciência para um determinado público com a finalidade de criar uma cultura científica que possibilite a evolução de pesquisas em determinada área.

Para verificar a pertinência dessa hipótese, vamos nos valer do estudo sobre gênero realizado por Fontanille (1999) e de suas reflexões sobre os níveis de pertinência semiótica (FONTANILLE, 2008), que foram orientadas na direção de uma semiótica do gênero por Portela e Schwartzmann (2012).

Para empreender tal reflexão, selecionamos como corpus a revista Actes Sémiotiques ${ }^{1}$ em sua plataforma digital. O periódico foi fundado em 1978, por A. J. Greimas e seus colaboradores, com o principal propósito de apresentar análises e divulgações na área da Semiótica que contribuíssem para a evolução das pesquisas nessa disciplina. De acordo com as informações presentes em sua política editorial, publicada em junho de 2013, a Actes Sémiotiques ambiciona contribuir e orientar ativamente para o crescimento da investigação semiótica de forma que não somente se espelhe no legado intelectual de Greimas, mas também para incentivar reflexões que envolvam novas questões e novos horizontes de pesquisas em semiótica². A publicação on-line da revista possibilitou uma maior acessibilidade, além de praticamente triplicar a participação de semioticistas-colaboradores em diferentes línguas.

Partiremos da distinção entre tipos textuais e tipos discursivos que, da perspectiva semiótica, constituem o gênero, para identificarmos as características textuais e discursivas do gênero de divulgação científica na revista Actes Sémiotiques. Posteriormente, aplicaremos à análise as instâncias formais dos níveis de pertinência semiótica que regem os gêneros. Objetivamos compreender como a divulgação científica é "revestida" por enunciados que, ao adquirirem uma composição geral,

\footnotetext{
${ }^{1}$ Disponível em: <http://epublications.unilim.fr/revues/as/> . Acesso em: 15. ago. 2017. ${ }^{2}$ Ressaltamos, ainda, que, de 1978 a 1987, o periódico foi subdividido em Actes sémiotiques - Bulletins e Actes sémiotiques - Documents. Após uma pausa nas publicações, em 1988, entre 1989 e 2012, ao nome do periódico foi adicionado o termo "nouveaux", passando a intitular Nouveaux actes sémiotiques. A partir de 2013, voltou ao título original: Actes sémiotiques.
} 
constituem o gênero discursivo científico. As perguntas que norteiam este artigo são: uma revista de divulgação científica atua de que forma na relação entre enunciador-enunciatário? Os elementos que a compõem facilitam o cotejo para pesquisadores-colaboradores? A revista Actes Sémiotiques promove diálogo com as demais especialidades e áreas do conhecimento, além da semiótica discursiva?

Para Greimas e Courtés (2012, p. 228), o termo "gênero" estava relacionado ao universo socioletal e, assim, foi definido como uma taxonomia veiculada aos discursos sociais manifestados no texto. Corroborando os autores, pressupomos que, por se tratar de uma revista destinada à divulgação do saber científico, a finalidade, assim como os elementos textuais e discursivos que a compõem, atua diretamente na relação dialógica entre enunciador e enunciatário. Nessa perspectiva, a relação dialógica é:

[...] promotora de um elo orgânico vivo entre a ciência, entendida como uma esfera ideológica constituída, e os estratos superiores da ideologia do cotidiano, que operam uma avaliação crítica viva dos produtos da ciência (GRILLO, 2013, p. 79-80).

Assim, entendemos que os enunciados presentes no discurso de divulgação científica são estabelecidos na regularidade de diferentes tipos de gênero como: artigos, resenhas, traduções, editoriais, entrevistas, entre outros, tendo a prática científica como denominador comum. O periódico Actes Sémiotiques particulariza-se, portanto, em uma primeira instância, pela exteriorização da ciência semiótica para fora da abrangência temática da revista, com a finalidade de criar uma cultura científica com o próprio enunciatário. "Não se trata, portanto, nem de um gênero nem de uma esfera, mas de relações dialógicas da esfera científica com outras esferas da atividade humana ou da cultura" (GRILLO, 2013, p. 89).

\section{Breves considerações sobre gênero}

A concepção de gênero desenvolvida por Fontanille (1999) nos permitirá explicitar, de forma breve, a configuração genérica de um gênero de divulgação científica. Bakhtin (2003) entende os gêneros do discurso como enunciados (orais e escritos) relativamente estáveis, determinados pelo caráter sócio-histórico e caracterizados, sobretudo, por um conteúdo temático, um estilo e uma construção composicional 
V. 9 (2)

14-32 maio-ago 2019

específica. Para o autor, os gêneros, mesmo configurados dentro de uma determinada atividade, são numerosos, heterogêneos e resultam em "traços gerais [...] demasiadamente abstratos e vazios" (BAKHTIN, 2003, p. 266). O gênero de caráter científico, tema deste trabalho, é definido por Bakhtin (2003, p. 263) como integrante dos "gêneros discursivos secundários", pois são organizados e desenvolvidos em "um convívio cultural mais complexo e relativamente muito desenvolvido e organizado (predominantemente o escrito)".

Sob essa perspectiva, esse gênero específico seria difundido, sobretudo, para comunidades particulares que buscam um conhecimento específico. Em Introdução ao pensamento de Bakhtin, Fiorin (2008, p. 6063) passa a discutir a noção de gênero do discurso como "um conjunto de propriedades formais a que o texto deve obedecer". Em outros termos, os gêneros seriam segmentados por traços textuais comuns e a configuração de gêneros diferentes se daria pelos enunciados construídos nos textos, bem como "os elementos (condições específicas e finalidades) da esfera da atividade literária que levam ao surgimento desse tipo de enunciado" (FIORIN, 2008, p. 60-63).

Em outras palavras, é impossível caracterizar uma tipologia fechada dos gêneros de discurso, justamente pela sua relação constitutiva com as práticas sociais. Fairclough (2001, p. 161), por exemplo, sugere que os gêneros correspondem muito estreitamente aos tipos de prática social. Para ele, "o sistema de gêneros que é adotado em uma sociedade particular, em um tempo particular, determina em que combinações e configurações os outros tipos ocorrem" (FAIRCLOUGH, 2001, p. 161).

Sobre gênero, Greimas e Courtés (2012, p. 228) afirmam que:

O gênero designa uma classe de discurso, reconhecível graças a critérios de natureza socioletal. Estes podem provir quer de uma classificação implícita que repousa, nas sociedades de tradição oral, sobre a categorização particular do mundo, quer de uma "teoria dos gêneros" que, para muitas sociedades, se apresenta sob a forma de uma taxionomia explícita, de caráter não científico. Dependente de um relativismo cultural evidente e fundada em postulados ideológicos implícitos, tal teoria nada tem de comum com a tipologia dos discursos que procura constituir-se a partir do reconhecimento de suas propriedades formais específicas. O estudo da teoria dos gêneros, característico de uma cultura (ou de uma área cultural) dada, não tem interesse senão na medida em que pode evidenciar a axiologia subjacente à classificação: ele pode ser comparado à descrição de outras etno e sociotaxionomias. 
Para a semiótica, o gênero tem relação direta com o universo socioletal em que está inserido e, como afirmam Portela e Schwartzmann (2012, p. 69), "a noção de gênero não é uma noção que tenha achado eco entre os semioticistas da escola greimasiana ou, se quisermos ir mais longe, entre as escolas semióticas contemporâneas". Greimas (1993, p. 10), em Maupassant, considerava que "o gênero é logicamente anterior a toda manifestação textual", o que acabou excluindo a questão do gênero do campo de pesquisa da semiótica, já que definir os gêneros textuais e discursivos equivaleria a tratar de uma construção anterior ao próprio texto, em termos de normatização ou, pior, especulação.

Fontanille (1999) retoma essa questão trazendo um novo olhar sobre gênero. O autor considera o termo "gênero" por meio da comparação e do reconhecimento de semelhanças (ou diferenças) entre os diversos textos, em outras palavras, tudo que um texto tem em comum (ou não) com outros textos é o que o coloca dentro de uma caracterização de gênero.

\section{A perspectiva semiótica de gênero discursivo}

Partindo da definição de Bakhtin (2003, p. 262), que afirma que os gêneros são "tipos relativamente estáveis de enunciados", Fontanille (1999, p. 161) acentua que os gêneros são mutáveis, classificados de acordo com a época e a cultura que os regem. Todavia, para o autor, mesmo que haja uma variação histórica e cultural dos critérios de distinção entre os gêneros, é preciso observar uma combinação de critérios que devem ser reconhecidos em um "esquema pancrônico", definição que eleva a importância da noção de "práxis enunciativa".

O conceito de práxis enunciativa nos auxilia a observar mudanças, variações, permanências, desaparecimento e surgimento dos gêneros. Segundo Fontanille (2007, p. 271), “[...] a práxis enunciativa está particularmente implicada no aparecimento e no desaparecimento dos enunciados e das formas semióticas no campo do discurso [...]". Assim, de acordo com o autor, a práxis enunciativa regula a "presença das grandezas discursivas no campo do discurso" (FONTANILLE, 2007, p. 271).

Nessa perspectiva, Fontanille (1999, p. 161-162) considera que cada gênero é constituído pela junção de "um tipo discursivo" e um "tipo textual", sendo a "práxis enunciativa" responsável pela presença de tipologias discursivas no campo discursivo que pode "convocar ou invocar enunciados". Grosso modo, essa composição de gênero é 
V. 9 (2)

$14-32$

maio-ago

2019

estruturada da seguinte forma: coerência (na relação com o discurso), coesão (na relação com o texto) e congruência (a reunião entre coesão e coerência - ou discurso e texto). ${ }^{3}$

Os tipos textuais estão relacionados ao plano da expressão e, de acordo com Fontanille (1999, p. 163), obedecem a dois critérios de classificação: longo vs. breve e aberto vs. fechado. Os conceitos longo e breve se relacionam à extensão da unidade de leitura, ao tempo da enunciação, à duração da história ou do acontecimento; já aberto e fechado correspondem à relação entre a unidade de leitura e a unidade de edição. A preocupação do autor, em relação a esses critérios, é com o todo de sentido do texto (como unidade de leitura) e se o sentido organizado é mantido isoladamente (na unidade de edição). A conjunção desses dois critérios estabelece quatro propriedades principais dos tipos textuais: recursividade (se longo e aberto), fragmentação (se breve e aberto), desdobramento (se longo e fechado) e concentração (se breve e fechado). Esses tipos textuais são compostos por um princípio de classificação que se relacionam à extensão (ou elasticidade) do discurso, em outros termos, uma mesma organização discursiva pode comportar vários tipos de textos, conforme a estratégia adotada.

A definição de um gênero é designada pelo tipo textual e, posteriormente, pelo tipo discursivo. Assim, o gênero se define, segundo Fontanille (1999, p. 168), em cinco aspectos:

1) Por seu tamanho relativo e pela duração da enunciação; 2) Por sua forma aberta ou fechada, do ponto de vista da duração, da edição e da leitura; 3) Pelos dominantes modais da enunciação, os atos de linguagem e as relações intersubjetivas que ele implica; 4) Pelos valores que ele aceita e coloca em circulação e pelas condições requeridas para isso; 5) Pelos tipos discursivos "nômades" e complementares que ele tolera.

Os tipos discursivos estão relacionados ao plano do conteúdo e são caracterizados por uma coerência que presume sistema de valores e relações hierárquicas e diferenciais, que também podem ser definidas a partir de dois critérios: o das modalidades da enunciação, que trata dos "contratos entre os sujeitos da enunciação, dos tipos de atos de linguagem e das modalizações dominantes do ponto de vista pragmático", e o das axiologias, que se preocupa com "os tipos de valores propostos assim como as condições de sua atualização e conhecimento no discurso" (FONTANILLE, 1999, p. 164).

${ }^{3}$ A congruência é um aspecto importante na análise de um gênero, pois assegura que um tipo discursivo seja definido por sua coerência, enquanto um tipo textual, por sua coesão. 
Essas modalizações são compostas em quatro pares distintos, que variam de acordo com o tipo de predicado modal, sendo elas: assumir e aderir (discurso persuasivo); dever e querer (discurso incitativo, podendo se tornar um discurso prescritivo se o dever for modalidade dominante); saber e o poder (discurso de habilitação) e ser e fazer (discurso de realização) (FONTANILLE, 1999, p. 165).

O critério das axiologias é definido por Fontanille (1999, p. 166-167) pela "intensidade de adesão" dos sujeitos aos valores manifestados nos discursos e quantidade de vezes que esses valores se manifestam. Essa "manifestação" pode ter intensidade forte ou fraca e extensão restrita ou ampla. Dessa combinação, quatro tipos discursivos são apresentados: valores exclusivos (forte e restrito, que são os valores de discursos moralistas, militantes, entre outros); valores discretos (fraco e restrito, que são os valores de discursos fracamente assumidos); valores participativos (forte e amplo, que são os valores de discursos com grande extensão de aplicação), e os valores difusos (fraco e amplo, que são valores com uma fraca adesão, como, por exemplo, os valores da ficção realista).

Para explicitar como se compõe cada tipo (textual e discursivo) de um gênero de divulgação científica, retomaremos antes, para fins de análise sobre o gênero, o percurso gerativo da expressão.

\section{Os níveis de pertinência semiótica e o percurso gerativo da expressão}

Fontanille (2005) propõe o percurso gerativo da expressão segundo uma hierarquia dos níveis de pertinência semiótica, propondo a análise a partir de três instâncias expressivas (experiência, instâncias formais e materiais) e seis níveis de pertinência do plano de expressão (signos, textos, objetos, cenas e práticas, estratégias e formas de vida) (Cf. Tabela 1). Trata-se de uma estruturação que ocorre no "mundo da expressão semiótica" por meio de diferentes planos de imanência e pertinência: 
V. 9 (2)

$14-32$

maio-ago

2019

Tabela 1 - Percurso gerativo do plano de expressão

\begin{tabular}{|c|c|c|}
\hline $\begin{array}{l}\text { Tipo de } \\
\text { experiência }\end{array}$ & Instâncias formais & Instâncias materiais \\
\hline Figuratividade & $\begin{array}{l}\text { Signos } \\
\downarrow\end{array}$ & $\begin{array}{l}\text { Propriedades sensiveis e materiais das } \\
\text { figuras }\end{array}$ \\
\hline Interpretação & $\begin{array}{c}\text { Textos enunciados } \\
\boldsymbol{\downarrow}\end{array}$ & $\begin{array}{l}\text { Propriedades sensiveis e materiais dos } \\
\text { textos }\end{array}$ \\
\hline Corporeidade & $\begin{array}{c}\text { Objeto } \\
\boldsymbol{\downarrow}\end{array}$ & $\begin{array}{l}\text { Propriedades sensiveis e materiais dos } \\
\text { objetos }\end{array}$ \\
\hline Prática & $\begin{array}{c}\text { Cenas predicativas } \\
\boldsymbol{} \\
\boldsymbol{K}\end{array}$ & $\begin{array}{l}\text { Propriedades sensiveis e materiais das } \\
\text { práticas }\end{array}$ \\
\hline Conjuntura & $\begin{array}{c}\text { Estratégia } \boldsymbol{k} \\
\downarrow\end{array}$ & $\begin{array}{l}\text { Propriedades sensiveis e materiais das } \\
\text { estratégias }\end{array}$ \\
\hline $\begin{array}{l}\text { Ethos e } \\
\text { Comportamento }\end{array}$ & Formas de vida $\boldsymbol{K}$ & $\begin{array}{l}\text { Propriedades sensiveis e materiais das } \\
\text { formas de vida }\end{array}$ \\
\hline
\end{tabular}

Fonte: Fontanille (2005, p. 36).

Cada experiência, de acordo com o modelo de hierarquia de níveis proposto por Fontanille (2008, p. 20-27), é associada a propriedades semióticas:

A experiência perceptiva e sensorial conduz às "figuras", a experiência interpretativa conduz aos "textos-enunciados", a experiência prática conduz às "cenas predicativas", a experiência das conjunturas conduz às "estratégias" etc.

Na conversão de uma experiência em conteúdos expressivos, a significação expressa em um nível de expressão formal não se restringe ao próprio nível, mas transcende para níveis superiores. A proposta de Fontanille (2008), em Pratiques Sémiotiques, permite-nos estudar o gênero levando em conta sua produção e circulação em determinado universo socioletal, "[...] nessa definição, o gênero não seria abordado somente no plano de imanência textual, mas em correlação com outros planos de imanência dos objetos e das práticas [...]" (PORTELA; SCHWARTZMANN, 2012, p. 84-85), formando o arranjo metodológico que segue: 
Tabela 2 - Planos de imanência

\begin{tabular}{|c|c|c|}
\hline Textos-enunciados & $\begin{array}{c}\text { Gêneros } \\
\uparrow\end{array}$ & $\begin{array}{c}\text { Propriedades textuais }{ }^{5} \text { genéricas } \\
\downarrow\end{array}$ \\
\hline Objetos & $\begin{array}{c}\text { Tipo de suporte } \\
\text { formal }\end{array}$ & $\begin{array}{c}\text { Propriedades morfológicas genéricas } \\
\text { Cenas práticas }\end{array}$ \\
$\begin{array}{c}\uparrow \\
\text { Tipo de prática }\end{array}$ & $\begin{array}{c}\downarrow \\
\text { Instruções de exploração }\end{array}$ \\
\hline
\end{tabular}

Fonte: Portela e Schwartzmann (2012, p. 8).

Sobre a tabela apresentada acima, Portela e Schwartzmann (2012, p. 85) reiteram que é por meio desse "esquema" que a prática é compreendida, pois, obedecendo à hierarquia dos níveis de pertinência, o gênero é regido pelos tipos de práticas e, tanto o gênero, quanto os tipos de práticas, são mediados pelo tipo de suporte formal.

\section{Os tipos textual e discursivo no gênero de divulgação científica}

Baseados nas propostas apresentadas por Fontanille (1999), entendemos os tipos textuais do gênero de divulgação científica pelas constantes do plano da expressão, que podem se modificar a depender do seu objeto-suporte, mas que sempre mantêm uma linha de coesão interna conformando seus conteúdos em seções, segundo sua política editorial.

No corpus selecionado, encontramos a seguinte disposição textual: 
V. 9 (2)

$14-32$

maio-ago

2019
Figura 1 - Imagem do site da revista actes sémiotiques

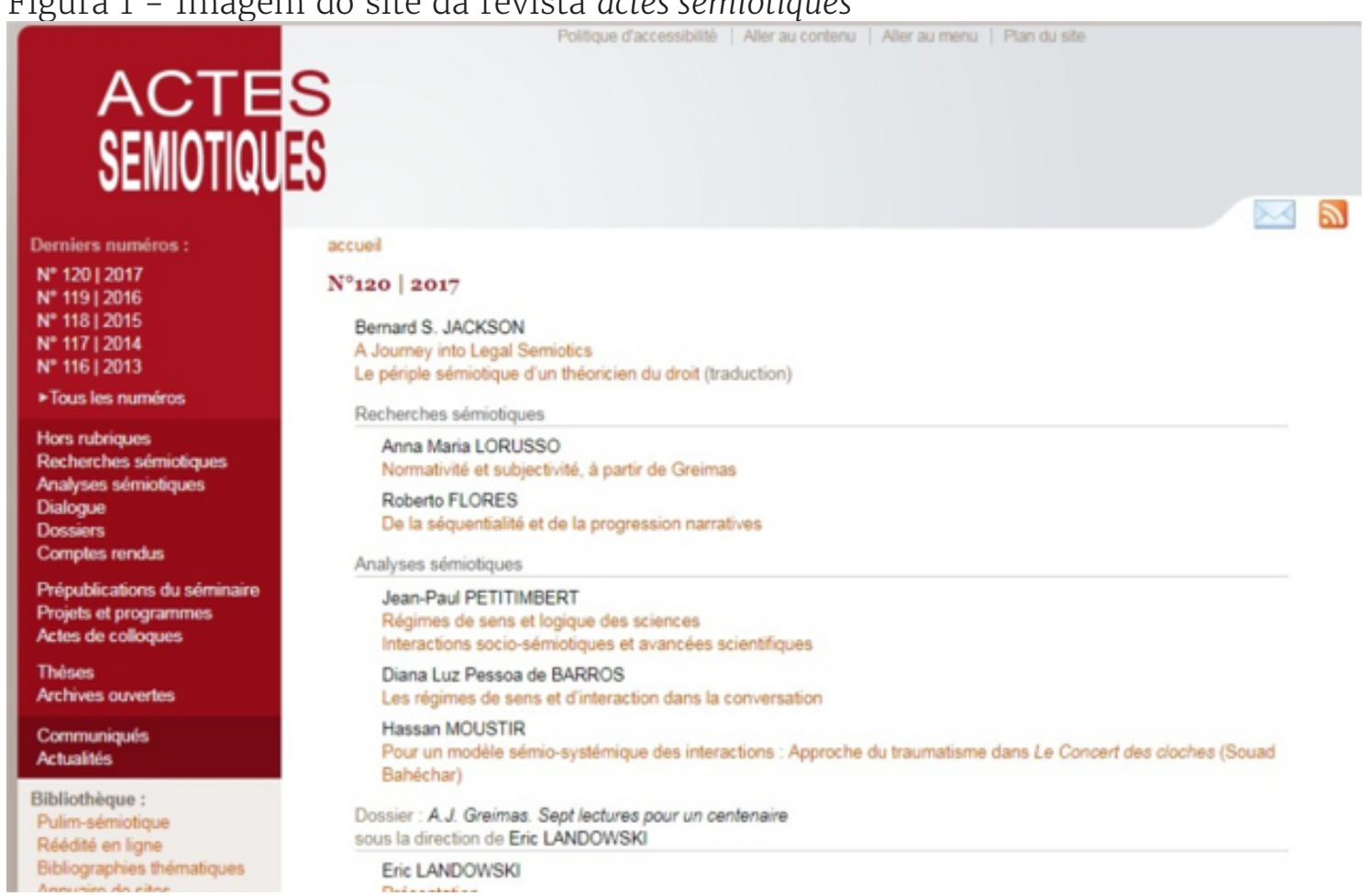

Fonte: nossa autoria.

Observamos que sua coesão está atrelada à organização das partes no interior de um todo, as quais dispõem de tópicos delimitados graficamente que possibilitam ao enunciatário acessar conteúdos distintos e específicos relacionados à disciplina semiótica. O nome do periódico em caixa alta, disposto na parte esquerda (acima) do site, já direciona o usuário ao conteúdo previsto no periódico, que é seguido pelas seções que são distribuídas em: Pesquisas semióticas, Análises Semióticas, Dossiê, Registros, Diálogos, entre outros segmentos de ordem específica que facilitam a busca pelo conteúdo desejado.

Os modos de inscrição dos textos, na disposição geral da revista Actes Sémiotiques, aparecem como formas fechadas em suas próprias estruturas organizacionais, como figuras constituídas pela ação das diferentes materialidades sensíveis do plano da expressão (cor, topologia, formas, linhas, entre outros). Os textos se conjugam a outros em cenas predicativas que lhe conferem eficácia enunciativa e pragmática (FONTANILLE, 2005). Essa eficácia enunciativa e pragmática a que se refere Fontanille (2005) é definida por Portela (2008, p. 103) como uma "dimensão pragmáticocognitiva das estratégias" que, grosso modo, é a relação entre uma prática discursiva maior relacionada a outras práticas que, interagindo, compõem a própria enunciação do objeto. Observando a revista como um todo, como uma prática de divulgação científica, as seções que a compõem formam toda a dimensão interativa dessa prática de divulgação científica. 
Assim, sendo um periódico que tem como objetivo divulgar trabalhos científicos específicos na área da semiótica, podemos considerá-lo como um texto longo, já que a revista não esgota em suas concretudes próprias a totalidade de sentidos por meio de textos. Podemos dizer que se trata de um texto aberto. Mesmo que, se constitua como um espaço privado, restrito, devido às coerções materiais que nele influem, na forma como esse gênero é estruturado. O que tem a ver, primeiramente, com o seu suporte formal, que determina a sua organização topológica: o acesso à revista pela plataforma digital -, a possibilidade de leitura isolada das seções de que o objeto dispõe, em que cada parte da revista tem um sentido legível em si, é ampliada por uma perspectiva de leitura extensa e em série.

Da combinação entre esses dois critérios, depreende-se uma propriedade distinta de tipo textual, a da recursividade, que, de acordo com Portela e Schwartzmann (2012, p. 78), "seria aquele cujos procedimentos permitem a reativação e o encaixe indefinidos das estruturas textuais". Em outros termos, as propriedades textuais presentes nesse tipo de gênero possibilitam a leitura de qualquer seção na revista sem precisar recorrer a outros tópicos, permitindo, assim, que os textos sejam lidos na unidade de edição.

Entremeadas à perspectiva geral da revista, temos as seções dispostas no site, que têm como função cotejar os resultados de uma dada pesquisa. A partir dessa perspectiva, temos outro tipo textual que pode ser definido como "longo/fechado", tendo como propriedade o desdobramento, que "mesmo explorando muitas possibilidades de expansão textual, permanece ainda sob o controle de um esquema global, que acaba por 'fechar' o texto" (PORTELA; SCHWARTZMANN, 2012, p. 78). Isso ocorre, pois, mesmo que tal seção seja cotejada, há um entorno textual correspondente à visão geral da revista que tem como objetivo específico discutir os desdobramentos científicos na área da semiótica.

Dessa primeira perspectiva de análise, teríamos, no nível da tipologia textual, as seguintes características: longo e aberto, por um lado, e longo e fechado, por outro. Essas tipologias ficariam representadas da seguinte forma:

Tabela 3 - Tipologia Textual Inicial

\begin{tabular}{|l|l|l|}
\hline & Categorias & Tipos Textuais \\
\hline Revista & Longo/aberto & Recursividade \\
\hline Seções & Longo/Fechado & Desdobramento \\
\hline
\end{tabular}

Fonte: nossa autoria. 
V. 9 (2)

14-32 maio-ago 2019

A maneira como o periódico é estruturado na plataforma virtual possibilita a separação de conteúdos por organizações temáticas em um processo abrangente que incorpora recursos, estratégias e quaisquer instrumentos empregados para divulgar dados científicos específicos. Sob esse aspecto, a revista Actes Sémiotiques organiza-se com o propósito de possibilidades de análises e reflexão sobre a teoria semiótica caracterizada pela propagação e difusão de saberes, ideias, valores e pontos de vista.

Nesse sentido, vale ressaltar que saber está sendo empregado sob o aspecto teórico apresentado por Fontanille (2007, p. 170): "tudo que caracteriza um 'discurso em ato'", e isso incluiria "as expressões afetivas, as avaliações axiológicas, as orientações e efeitos argumentativos, e, consequentemente a constituição dos sistemas de valores do discurso". Nessa perspectiva, Fontanille (2007) afirma que, enquanto a modalidade representa apenas um dos múltiplos aspectos da atividade enunciativa, a modalização emana em geral da manifestação da atividade enunciativa.

Os tipos discursivos na revista Actes Sémiotiques, no critério de modalidades da enunciação, apresentado por (FONTANILLE, 1999, p. 164), são estruturados pelas modalizações do "saber e poder" e, mesmo que possam ter a presença da modalização do "fazer", nesse caso, não estariam sobremodalizados a ponto de definir um discurso performativo no enunciatário.

Outrossim, o caráter de divulgação científica permite conjecturar os tipos de valores propostos e as condições de atualização e conhecimento do discurso. Esse traço comum se manifesta nas configurações discursivas particulares, com o estabelecimento de um contrato fiduciário ${ }^{4}$ entre os sujeitos desse universo compartilhado. É por meio de um saber ou poder que se institui o contrato, fundado sobre os efeitos de sentido de verdade e realidade que se firmam como um "constructo modal", legitimado em função do valor de verdade atribuído aos simulacros (SCHWARTZMANN, 2009, p. 35). Dessa junção, podemos ainda encontrar subtipos definidos pelas modalidades dominantes no discurso de habilitação, em que "o saber enquanto dominante modal caracteriza os discursos informativos (para o saber) e os discursos de aprendizagem (para o saber-fazer)" (PORTELA; SCHWARTZMANN, 2012, p. 80). Nesse caso, a práxis enunciativa se organizaria entre ajustamentos das sobremodalizações: poder-fazer-saber.

4 Segundo Greimas e Courtés (2012, p. 101), o contrato fiduciário "visa estabelecer uma convenção fiduciária entre enunciador e enunciatário, referindo-se ao estatuto veridictório (ao dizer-verdadeiro) do discurso enunciado". 
Quanto ao segundo critério, proposto por Fontanille (1999, p. 164), da combinação da forte intensidade de adesão e da ampla extensão e quantidade de manifestações, presentes no discursivo de divulgação científica, temos o valor participativo, já que a revista, por sua materialidade como objeto de veiculação na plataforma digital (internet), tem tempo de duração indeterminado, o que possibilita a existência de um fluxo contínuo de textos que forcem uma "atualização" a novos parâmetros de divulgação da disciplina semiótica, o que presume uma prática de divulgação científica constituída em dois sentidos: (a) na prática de acesso aos textos específicos da revista; (b) na própria interpretação dos enunciados, que se estende e se modifica, dando origem a novas textualizações suscetíveis de serem publicadas na própria revista.

\section{Divulgação científica: a prática semiótica e sua configuração}

O site da revista, objeto-suporte do texto-enunciado, é composto, basicamente, pelo layout de entrada, em que o usuário pode ver todas as seções de que o site dispõe seguido dos links que dão acesso ao conteúdo que estão dispostos de acordo com as imagens abaixo: 


\section{9 (2) \\ $14-32$}

maio-ago

2019

28

Figura 2 - imagem do site da revista

Actes Sémiotiques

Disposição esquerda do site

\section{ACTES SEMIOTIUES}

Derniers numéros :

$N^{\circ} 120 \mid 2017$

$N^{\circ} 119 \mid 2016$

$N^{\circ} 118$ | 2015

$N^{\circ} 117 \mid 2014$

$N^{\circ} 116 \mid 2013$

-Tous les numéros

Hors rubriques

Recherches sémiotiques

Analyses sémiotiques

Dialogue

Dossiers

Comptes rendus

Prépublications du séminaire

Projets et programmes

Actes de colloques

Thèses

Archives ouvertes

Communiqués

Actualités

Bibliothèque :

Pulim-sémiotique

Réédité en ligne

Bibliographies thématiques

Annuaire de sites

Index :

Auteurs

Mots-clés

Auteurs cités

Oeuvres commentées :

Auteurs

Liste chronologique

Fonte: nossa autoria.

Figura 3- imagem do site da revista Actes Sémiotiques Miolo do site

accueil

$\mathrm{N}^{\circ} 120 \mid 2017$

Recherches sémiotiques

Analyses sémiotiques

Dossier : A.J. Greimas. Sept lectures pour un centenaire

sous la direction de Eric LANDOWSKI

Dialogue

Comptes rendus

Projets et programmes

Rédité en ligne

Fonte: nossa autoria. 
Figura 4 - imagem do site da revista Actes Sémiotiques

Parte superior do site

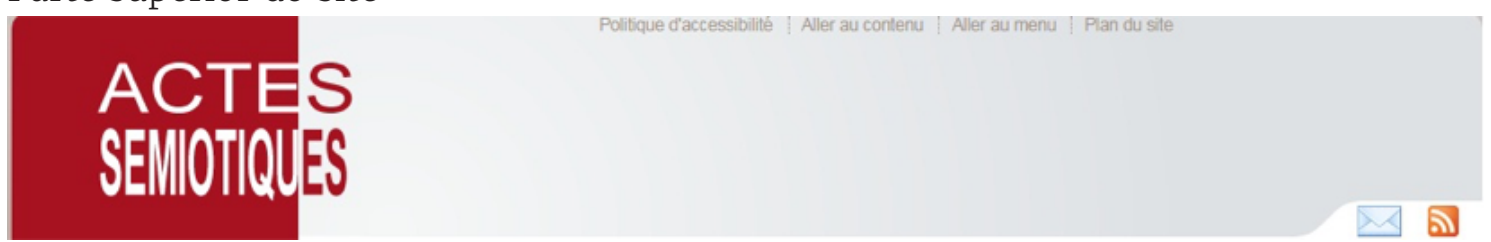

Fonte: nossa autoria.

Figura 5 - imagem do site da revista Actes Sémiotiques Parte inferior do site

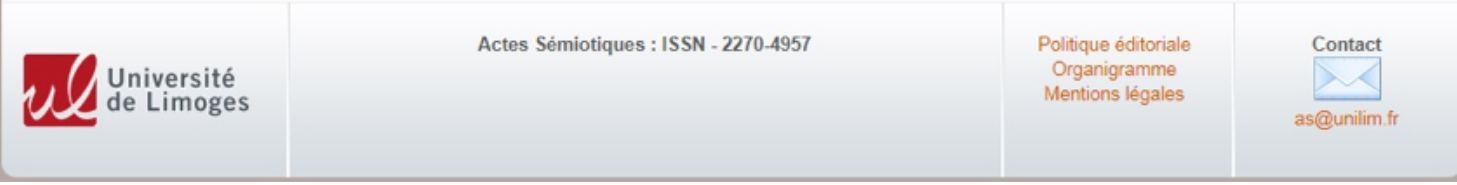

Fonte: nossa autoria.

Ao cotejarmos o texto-enunciado com seu objeto-suporte, percebemos que o site se subdivide em 30 seções, que são intercaladas em pesquisas recentes, pesquisas (de ordem cronológica), acervo, teses, arquivos, política editorial, análises e lançamentos. Cabe ao enunciatário procurar pelo assunto de seu interesse por meio das seções da revista. Desse modo, a cena predicativa ou cena prática pode ser compreendida como a forma pela qual a experiência de uma prática é manifestada (SCWARTZMANN, 2009, p. 93). Sua apreensão se faz pela observação da prática configurada na forma de uma cena, ou seja, por um conjunto de predicados (processos) ou atos de enunciação que instauram:

[...] papéis actanciais desempenhados, entre outros, pelos próprios textos ou imagens, por seus objetos-suportes, por elementos do ambiente, pelo transeunte, pelo usuário ou pelo observador, tudo o que forma a 'cena' típica de uma prática (FONTANILLE, 2008, p. 23).

Assim, podemos apreender a cena prática pela presença de elementos comuns recorrentes na descrição dos processos (predicados/ atos) que compõem a cena prática do corpus estudado: os pesquisadores especializados que estudam o texto de pesquisadores; o pesquisador que escreve para outros pesquisadores; os pesquisadores de outras áreas que estudam o texto de pesquisadores da área de semiótica.

Abaixo, a tabela que sintetiza a prática de leitura desse gênero: 
V. 9 (2)

14-32

maio-ago 2019

Tabela 4 - Prática de leitura da Revista Actes Sémiotiques

\begin{tabular}{|c|c|c|}
\hline Texto-Enunciado & Revista científica & $\begin{array}{l}\text { Discurso de Habilitação e de } \\
\text { valores participativos }\end{array}$ \\
\hline Objeto-Suporte & $\overbrace{T}^{\text {Internet }}$ & Divulgação da teoria semiótica \\
\hline Cena-prática & $\begin{array}{l}\text { Prática de leitura de textos de } \\
\text { divulgação científica }\end{array}$ & Popularizar a ciência semiótica \\
\hline
\end{tabular}

Fonte: nossa autoria.

Todavia, é preciso destacar que essa não é a única forma de leitura do texto-enunciado, já que o discurso científico é modalizado, sobretudo, pelo saber. Sobre esse aspecto, levando em conta as pesquisas de Dondero (2010), sobre a divulgação científica e as três práticas que esta presume (interrogação, estabilização e institucionalização), podemos perceber que a revista apresenta a teoria semiótica ora já avaliada ora cujo processo de avaliação está avançado (ou estruturado). Trata-se, portanto, de uma prática institucional, em que os textos apresentados e divulgados são caracterizados pela pesquisa especializada, chancelada por avaliadores da área que também são autores nos números da AS.

A divulgação científica parte de uma temática específica, mas também abrangente, já que promove diálogos entre a semiótica discursiva, as demais semióticas e as diversas áreas do conhecimento, e sua prática apresenta um grau maior de atualização, já que se torna um meio de circulação textual e discursivo contínuo devido à procura pelo saber que dá conta de um universo de formas estabilizadas e aceitas pela comunidade científica.

\section{Considerações finais}

Ao examinarmos o processo de caracterização do gênero de divulgação científica pela proposta de Fontanille (1999; 2008) e de Portela e Schwartzmann (2012), observamos que, no entrecruzamento dos tipos textuais e discursivos presentes no texto, o sentido do texto de divulgação científica, como um gênero particular de discurso, transpõe o discurso específico de uma prática do campo científico para uma determinada comunidade. A maneira como o periódico é diagramado e os agrupamentos que separam os assuntos por organizações temáticas possibilitam ao enunciatário navegar entre diversas alternativas de competencialização, segundo seu grau de conhecimento da teoria. 
A prática de divulgação científica busca ampliar o conhecimento do enunciatário sobre temas relevantes de uma área específica, ao mesmo tempo em que lhe apresenta o modo como a disciplina de que se ocupa está institucionalizada. Além disso, como vimos no caso da AS, a internet como suporte de periódicos científicos permite a construção de um enunciatário que não apenas lê, mas usa, pratica a atividade científica: pesquisa, cruza dados e indexa autores e temas.

\section{Referências}

BAKHTIN, M. Estética da criação verbal. Tradução de Paulo Bezerra. São Paulo: Martins Fontes, 2003.

CUNHA, A. G. Dicionário etimológico Nova Fronteira da língua portuguesa. Rio de Janeiro: Nova Fronteira, 1982.

DONDERO, M. G. Sémiotique de l'image scientifique. Signata: PULg, n. 1, 2010, p. 111-175.

FAIRCLOUGH, N. Discurso e mudança social. Tradução de Izabel Magalhães. Brasília: Editora [da] Universidade de Brasília, 2001.

FERREIRA, A. B. H. Novo Dicionário Aurélio da Língua Portuguesa. $3^{\mathrm{a}}$. ed. Rio de Janeiro: Regis, 2004.

FIORIN, J. L. Elementos de análise do discurso. 14. Ed. São Paulo: Contexto, 2008.

FONTANILLE, J. Le genre. In: Sémiotique et littérature: Essais de méthode. Paris: PUF, 1999, p. 159-187.

Significação e visualidade - exercícios práticos. Tradução de Elizabeth B. Duarte e Maria Lilia D. de Castro. Porto Alegre: Sulina, 2005. Contexto, 2007.

Semiótica do discurso. Tradução Jean Cristtus Portela. São Paulo:

FONTANILLE, J. Pratiques sémiotiques. Paris: PUF, 2008.

GREIMAS, A. J. Maupassant: a semiótica do texto: exercícios práticos. Tradução de Teresinha Michels e Carmen Gerlach. Florianópolis: Editora [da] UFSC, 1993.

.; COURTÉS, J. Dicionário de Semiótica. São Paulo: Contexto, 2012.

GRILLO, S. V. C. Gêneros primários e gêneros secundários no círculo de Bakhtin: implicações para a divulgação científica. Alfa: Revista de Linguística. São Paulo, n. 52, v. 1, p. 57-79, 2008.

Divulgação científica: linguagens, esferas e gêneros. 2013. 333f. Tese apresentada ao Departamento de Letras Clássicas e Vernáculas. Faculdade de Filosofia, Letras e Ciências Humanas, Universidade de São Paulo, São Paulo, 2013. 
V. 9 (2)

$14-32$ maio-ago 2019

JACOBI, D. Textes et images de la vulgarisation scientifique. Berne: Peter Lang, 1987.

PORTELA, J. P. Semiótica midiática e níveis de pertinência. In: DINIZ, M. L. V. P.; PORTELA, J. C. (Org.). Semiótica e mídia: textos, práticas, estratégias. Bauru, SP: Unesp/Faac, 2008. p. 93-113

PORTELA, J. C; SCHWARTZMANN, M. N. A noção de gênero em semiótica. In: .; BEIVIDAS, W.; LOPES, I. C.; SCHWARTZMANN, M. N. (Org.). Semiótica: Identidades e diálogos. São Paulo: Cultura Acadêmica, 2012. p. 6998.

SANTOS, F. K. R.; PORTELA, J. C. A comunicação científica na revista Actes Sémiotiques: práticas e estratégias de difusão do saber científico. Diálogos Pertinentes: Revista Científica de Letras, Franca, v. 14, n. 1, p. 53-75, 2018.

SCHWARTZMANN, M. N. Cartas marcadas: Prática epistolar e formas de vida na correspondência de Mário de Sá-Carneiro. 2009. 293f. Tese (Doutorado em Linguística e Língua Portuguesa) - Faculdade de Ciência e Letras de Araraquara, Universidade Estadual Paulista, Araraquara, 2009. 